\title{
A importância da discussão das questões de gênero no âmbito escolar
}

\author{
La importancia de la discusión de las cuestiones de género en el ámbito \\ escolar
}

\author{
The importance of discussing gender issues in school
}

\author{
Ana Beatriz Antunes Rezende Tolfo ${ }^{1}$
}

\begin{abstract}
Resumo
O referido trabalho aborda a importância da discussão de gênero nas escolas, o papel do professor nesta discussão e a maneira como deve ser trabalhado este tema. O questionamento metodológico usado foi a pesquisa qualitativa subjetiva através da leitura de depoimentos, livros e artigos sobre o tema a ser desenvolvido. A finalidade do desenvolvimento do tema é de obter um maior conhecimento e uma maior clareza sobre a discussão de gênero no âmbito escolar, sua importância, características, o papel do professor e da escola e as consequências esperadas ao trabalhar este tema em sala de aula. Sendo a escola uma instituição que deve possibilitar o desenvolvimento do pensamento crítico partindo da compreensão sobre as diferenças corporais e sexuais que a sociedade muitas vezes impõe, tendo uma função fundamental na desmistificação destas diferenças, sendo também uma importante ferramenta na construção de valores e atitudes, as quais permitam obter-se um olhar mais crítico, reflexivo, compreensivo e tolerante sobre as identidades de gênero e sexual. Através deste trabalho buscou-se o esclarecimento sobre padrões e tendências, suas tipologias, seus impactos e mudanças ao longo do tempo.
\end{abstract}

Palavras-chaves: Gênero. Escola. Discussão. Professor. Importância. Simone de Beauvoir.

\section{Resumen}

Este trabajo aborda la importancia de la discusión de género en las escuelas, el papel del profesor en esta discusión y la manera como debe ser trabajado este tema. El cuestionamiento metodológico utilizado fue la investigación cualitativa subjetiva a través de la lectura de testimonios, libros y artículos sobre el tema a ser desarrollado. La finalidad del desarrollo del tema es obtener un mayor conocimiento y una mayor claridad sobre la discusión de género en el ámbito escolar, su importancia, características, el papel del profesor y de la escuela y las consecuencias esperadas al trabajar este tema en el aula. Siendo la escuela una institución que debe posibilitar el desarrollo del pensamiento crítico partiendo de la comprensión sobre las diferencias corporales y sexuales que la sociedad muchas veces impone, teniendo una función fundamental en la desmitificación de estas diferencias, siendo también una importante herramienta en la construcción de valores y actitudes, que permitan obtener una mirada más crítica, reflexiva, comprensiva y tolerante sobre las identidades de género y sexual. A través de este trabajo se buscó el esclarecimiento sobre patrones y tendencias, sus tipologías, sus impactos y cambios a lo largo del tiempo.

Palabras claves: Género. Escuela. Discusión. Maestro. Importancia. Simone de Beauvoir.

\begin{abstract}
This paper discusses the importance of gender discussion in schools, the role of the teacher in this discussion and the way in which this topic should be addressed. The methodological questioning used was the subjective qualitative research through the reading of testimonials, books and articles on the topic to be developed. The purpose of the development of the theme is to obtain a greater knowledge and clarity about the discussion of gender in the school context, its importance, characteristics, the role of the teacher and the school and the expected consequences in working this theme in the classroom. Being the school an institution that should
\end{abstract}

\footnotetext{
${ }^{1}$ Mestranda em Educação; UNIPAMPA; Jaguarão; RS; Brasil; bia.tolfo@ hotmail.com
} 
enable the development of critical thinking starting from the understanding about the corporal and sexual differences that society often imposes, having a fundamental function in the demystification of these differences, being also an important tool in the construction of values and attitudes, which allow for a more critical, reflexive, understanding and tolerant view on gender and sexual identities. Through this work we sought clarification on patterns and trends, their typologies, their impacts and changes over time.

Keywords: Gender. School. Discussion. Teacher. Importance. Simone de Beauvoir.

\section{Introdução}

A questão de gênero ainda é um tema que gera bastante polêmica, devido em grande parte à falta de informação por parte das pessoas. A sociedade está ambientada na estipulação de gênero, nas formas assimétricas de como o 'homem' e a 'mulher' devem agir, pensar, se vestir, comer e viver. As leis muitas vezes eram e algumas ainda são discriminatórias e exclusivistas que serviram e servem de instrumento de consolidação da desigualdade e assimetria na relação tanto entre homens e mulheres como entre brancos e negros, além de todas as pessoas que se identificam LGBTs. Os direitos humanos, durante muito tempo, trataram a questão das mulheres de forma secundária, como se seus direitos, lutas e conquistas estivessem atrelados aos direitos do homem. O homem sempre foi o paradigma dos direitos humanos de toda humanidade, como se não existissem outros paradigmas ou setores sociais mais vulneráveis, como as mulheres, crianças, idosos, negros, índios, migrantes, homossexuais, trans-gêneros, transexuais, deficientes físicos e mentais.

As sociedades estabeleceram um patamar de inferioridade e submissão em relação ao homem, não somente na seara doméstica, no direito familiar, mas no cenário público, como, por exemplo, no mercado de trabalho, através do pagamento de remuneração inferior à percebida pelos homens e brancos pelo exercício de funções semelhantes ou da dupla jornada de trabalho. A discriminação também foi e ainda é sentida nos espaços públicos e privados de poder que, refletiam a tímida participação política das mulheres, negros e gays quase sempre limitada ou proibida.

Uma autora que discorre sobre as questões de gênero em um de seus livros, o qual é o 'O segundo sexo', é Simone de Beauvoir no qual ela dialoga sobre os papéis que nos obrigam a representar em sociedade, sobre as consequências, dificuldades, sofrimento e luta para quebrar estes estigmas tão antigos. E apesar deste livro ter sido lançado em 1949, ele mostrase também atual, pois infelizmente alguns dogmas são difíceis de romper e extinguir-se de tão erroneamente enraizados na sociedade.

Mesmo com os consideráveis avanços nas últimas décadas a história das relações de gênero ainda é um tema em construção. Por certo, já houve notável desenvolvimento do 
estudo da temática em pouco tempo, mas a consolidação desse campo de estudos ainda é muito recente.

A discussão sobre gêneros em sala de aula é importante, pois é uma ferramenta de diálogo, que nos permite debater sobre o tema, aprender a respeitar e compreender as individualidades em sociedade, sendo todos nós cidadãos que merecemos reconhecimento, aceitação e o poder de decidirmos e quebrarmos os padrões em nossas vidas.

A pesquisa para o referido trabalho mostrou-se complexa, pois infelizmente ainda temos certa carência em materiais sobre o tema. Mas acredito que esta pesquisa será de grande valia, tanto para um maior conhecimento pessoal de minha parte como para endossar ainda mais a disponibilidade de ofertas de pesquisa sobre este tema.

\section{A importância das questões de gênero no âmbito escolar}

\subsection{Simone de Beauvoir e a concepção de gênero}

Pode-se dizer que a ideia central do conceito de gênero nasceu através dos pensamentos da escritora francesa Simone de Beauvoir, uma importante escritora e feminista na história, precursora da "Segunda Onda" do feminismo, de acordo com Scholz (2010). Uma de suas principais obras é o Segundo Sexo (1949), no qual ela discorre sobre as inúmeras construções sociais sobre ser homem e sobre ser mulher, quais mitos, destinos biológicos, condições do ser, posições sociais, diferenças em termos de educação e infância, relações com os pais e etapas do ciclo vital do ser humano. Como se percebe ao analisar esta citação:

\footnotetext{
"Não acredito que existam qualidades, valores, modos de vida especificamente femininos: seria admitir a existência de uma natureza feminina, quer dizer, aderir a um mito inventado pelos homens para prender as mulheres na sua condição de oprimidas. Não se trata para a mulher de se afirmar como mulher, mas de tornaremse seres humanos na sua integridade."
}

Beauvoir defende também que duas desmamas são importantes para compreender a generificação do sujeito na infância: a desmama da nutriz, do todo, pela qual o sujeito se acha abandonado no mundo e procura justificar sua existência; e a outra desmama, pela qual a sedução da criança é reprimida. Porém, a autora percebe que nessa segunda desmama, as meninas são, inicialmente, privilegiadas, pois continuam a aceitar que elas sentem nos colos dos pais, seu universo é outro, enquanto que o menino, ao negar-lhe as carícias, ele se torna 
mais rude. O que não é o ideal, pois tanto filhos como filhas merecem e precisam do carinho e proteção familiar durante a infância e até mesmo na vida adulta.

Claramente, esses processos vão moldando a feminilidade ou a masculinidade da criança, tornando-os distintos, assimétricos.

\subsection{Contextualizando gênero}

Ao se propor a discussão sobre o que é a questão de gênero nas escolas é importante que se tenha conhecimento de que o conceito é diferente da ideia de sexo. Ou seja, o sexo está relacionado com aspectos bio-fisiológicos, que distinguem as diferenças corporais entre homem e mulher.

Porém, o sexo não determina por si só a identidade de gênero ou orientação sexual de uma pessoa. A orientação sexual, por exemplo, refere-se à atração que sentimos por outras pessoas e envolve além das questões sexuais as questões sentimentais.

Com o desenvolvimento da compreensão sobre as diferenças corporais sexuais a sociedade cria ideias e valores sobre o que significa ser homem ou mulher, feminino ou masculino, estas são as chamadas representações de gênero. Nesta perspectiva, a questão de gênero está ligada à forma como a sociedade cria os diferentes papéis sociais e comportamentos relacionados aos homens e às mulheres, como por exemplo, nas cores das roupas (rosa é de menina e azul de menino), nas brincadeiras (boneca é de menina e bola é de menino), na forma de relacionar-se e de assumir responsabilidades.

As relações de gênero criam padrões fixos do que é próprio para o feminino e para o masculino e reproduzem estas regras como um comportamento natural do ser humano criando condutas e modos únicos de se viver sua natureza sexual. Isto significa dizer que a questão de gênero têm uma ligação direta com a forma como estão organizadas na sociedade os valores, desejos e comportamentos acerca da sexualidade.

Embora a definição do que é ser homem ou mulher tenha surgido a partir de uma divisão biológica, a experiência humana nos mostra que um indivíduo pode ter outras identidades que refletem diferentes representações de gênero (como os transexuais e transgêneros) e que não se encaixam nas categorias padrões.

De acordo com a escritora Ruth Rocha (1998) no livro Faca sem ponta, galinha sem pé, no qual ela conta a história de dois irmãos, Joana e Pedro, que enfrentam as diferenças pré estabelecidas pela sociedade entre meninos e meninas. No livro essas diferenças são representadas pela permissão ou não dos dois irmãos em participar de brincadeiras consideradas de meninas ou meninos. Assim, as brincadeiras e atividades escolares devem 
buscar o revezamento dos educandos nos papéis sendo eles preenchidos indiscriminadamente por alunos ou alunas, buscando vivenciar momentos agradáveis e se permitir ir além de formas de agir impostas pela sociedade.

\title{
2.3 A escola como espaço de discussão sobre as questões de gênero
}

Em sala de aula, deve-se visar trabalhar a questão de gênero na sociedade a fim de ampliar a visão dos alunos sobre o masculino e o feminino, de provocar uma reflexão sobre as relações que foram construídas de forma desigual, elaborar conceitos, identificar preconceitos e trabalhá-los. Pode-se trabalhar através de análises de músicas, textos, programas de televisão, contação de histórias, teatro, vídeos, imagens, discussões, oficinas e grupos de estudo. Assim Bruno Maia listou, em debate na Câmara dos Vereadores de São Paulo, algumas das dezenas de conferências internacionais, tratados, convenções e acordos que estarão sendo negligenciados caso os Planos Municipais de Educação excluam os termos ligados a gênero:

\begin{abstract}
"Um PME que contemple as discussões de gênero diz muito mais respeito às mulheres, que são $50 \%$ da população. Discutir gênero nas escolas significa questionar a violência contra a mulher e desconstruir a mentalidade machista. Questionar em sala de aula a razão delas terem salários menores e espaço reduzido nos parlamentos. [Questionar isso] é, inclusive, ir na direção de documentos internacionais para a promoção de direitos das mulheres que vai desde a Carta das Nações Unidas a Declaração dos Direitos Humanos, passando pela Convenção Interamericana sobre a Concessão dos Direitos Civis às Mulheres que outorgou às mulheres os mesmos direitos civis que gozam os homens, [negar o gênero] é passar por cima da Convenção sobre os Direitos Políticos da Mulher, de 1953, a Convenção da Organização Internacional do Trabalho (OIT), de 1951, que dispõe sobre igualdade de remuneração entre gêneros, a Convenção da OIT de 1952 que versa sobre o amparo materno, a Convenção da OIT de 1958 que dispõe sobre a descriminação em matéria de emprego, a [resolução da] 156 da OIT de 1981, que estende aos homens a responsabilidade sobre a família, a Convenção Americana de Direitos Humanos de São José, a Convenção Mundial de Mulheres da Cidade do México, que reconheceu o direito da mulher à integridade física, inclusive, à autonomia de decisão sobre o seu corpo e o direito à maternidade opcional, a Convenção para Eliminar Todas as Formas de Discriminação sobre a Mulher, de $\underline{79}$, assim como as conferências mundiais sobre a mulher de Copenhague e Nairóbi, de 80 e 85, também a Convenção Interamericana para Prevenir, Punir e Erradicar a Violência Contra a Mulher, que aconteceu em Belém do Pará de 1994 e uma série de compromissos internacionais assumidos pelo Brasil em nome da igualdade de gênero. Aí você vê nessa Casa mulheres e meninas recrutadas em suas comunidades religiosas mostrando cartazes que dizem não ao gênero.”
\end{abstract}

Nota-se no âmbito escolar um reflexo da nossa sociedade sexista, que ora dá vantagens a um gênero ou a outro, além de meninos, em sua maioria, desde pequenos, terem comportamentos machistas e de opressão em relação às meninas e ao comportamento delas. É 
importante que o professor ao trazer este tema para sala de aula esteja preparado e bem informado, pois este é um tema que ainda causa certa polêmica.

No livro Educar meninas e meninos: relações de gênero na escola, a autora Daniela Auad traz à tona a questão da escola mista relacionando-a com a ideia de coeducação com base na análise de práticas escolares e no debate contemporâneo sobre o tema, dialogando com estudiosas feministas que teorizam sobre a questão. Ela argumenta que a escola mista pressupõe a coeducação, mas não é suficiente para a efetivação da mesma e que as identidades de gênero são construídas pelos sujeitos ao se identificarem, social e historicamente. Ao longo do livro, é defendida a igualdade com respeito às diferenças e é mostrada como isso pode ocorrer na prática escolar, numa linguagem simples e acessível a qualquer pessoa que se interesse pela questão.

A autora também analisa a história da implantação da escola mista no Brasil, verificando quais conteúdos de ensino, normas, uso do espaço físico, técnicas e modos permitidos de pensar, sentir e agir se constituíram como mecanismos que perpetuam a separação e a hierarquização entre homens e mulheres o que causa, muitas vezes, a evasão escolar. Conforme a autora, as supostas diferenças sexuais naturais entre meninos e meninas são usadas pelo professor para conduzir a classe e manter a disciplina e a ordem, como por exemplo, as diferentes maneiras de se distribuírem meninos e meninas no espaço da sala de aula.

Confrontando suas próprias pesquisas no Brasil com estudos que descrevem a realidades escolares em outros países da América Latina e da Europa, percebe-se que os meninos, diferentemente das meninas, têm tendência a ocupar grandes espaços e se envolvem mais do que elas em atividades dinâmicas que requerem uma expressão corporal mais ampla. Assim, as relações de gênero influenciam o modo como meninos e meninas se expressam corporalmente e aproveitam diferentemente as possibilidades de movimentos, jogos e brincadeiras.

Assim, o tradicional sistema educacional brasileiro coloca o desafio de se combater a promoção das desigualdades de gênero, uma vez que tais desigualdades não são condizentes com uma sociedade democrática. A autora constata que alunas, alunos, professoras, agentes escolares, diretoras, coordenadoras e pesquisadoras podem estar na fronteira entre, de um lado, as práticas escolares nas quais as relações de gênero ainda são desiguais e, de outro, a possibilidade de construção de um projeto de coeducação. Para a efetiva concretização desse projeto de política educacional, Daniela Auad propõe uma transformação de diversos níveis da educação, englobando não apenas a legislação, o sistema educativo, as unidades escolares 
e os currículos, como também a capacitação e formação do profissional, a paridade do professorado, os livros didáticos e a interação entre professoras, professores, alunos e alunas. Traça assim um possível caminho para uma política pública de igualdade de gênero a partir da escola.

Assim, concluo que a discussão aberta sobre as questões de gênero é de fundamental importância na construção do ser social que é o aluno, pois a sua formação e seu modo de agir afetam diretamente todo o meio em que ele está inserido. Deve-se valorizar o caráter, os sentimentos e as ações das pessoas, sem forçá-las a se encaixar em padrões ou discriminá-las por suas opções e sexualidade. Desse modo, se construirá uma sociedade mais maleável, menos discriminatória e violenta, na qual as pessoas tenham a liberdade e o respeito para se descobrirem e se construírem de acordo com as suas vontades e crenças.

\subsection{O papel do professor como mediador no diálogo em sala de aula}

A escola é constituída e edificada por toda a sua comunidade, assim como o gestor, a equipe diretiva, os funcionários, pais, alunos e professores têm seus papéis na organização e sucesso em todas as atividades no âmbito escolar. Sendo necessário que toda comunidade esteja envolvida na implementação e construção do conhecimento e desenvolvimento dos alunos.

O professor deve atuar de forma imparcial, mas sempre ressaltando e fazendo prevalecer o respeito com as percepções dos alunos e suas individualidades, os instigando e auxiliando na desconstrução de preconceitos e ideias prontas e pré concebidas. O aluno deve ser estimulado a pensar, refletir e perceber tudo que o rodeia, os costumes, o racismo, a homofobia, as desigualdades, as diferentes percepções que existem em sociedade e principalmente a respeitar e compreender que todos temos nossas individualidades e que temos os mesmos direitos.

Deve-se priorizar em sala de aula a inclusão e fazer com que todos os alunos sejam de forma igualitária, independente de qual gênero este se identifique. A abordagem do assunto nas escolas pode até deixar alguns pais receosos, mas é necessário entender que é importante que o respeito às diferenças esteja presente no currículo. Informar é o primeiro passo para a quebra do preconceito.

A maneira que o tema é tratado em sala de aula deve ser feita de forma delicada, afinal a homossexualidade e os gêneros ainda são tabus. As questões relacionadas à sexualidade devem ser trabalhadas sempre aproximando o tema dos direitos e deveres dos cidadãos e do 
respeito e à diversidade humana. Deve-se debater os assuntos conforme a necessidade da classe, conforme o aluno vá questionando.

A desigualdade de gênero persiste, mesmo com um maior número de mulheres e meninas frequentando as escolas e ocupando mais cargos na política e em cargos de chefia. A discriminação ainda existe quando se trata em ter a mesma facilidade de acesso ao trabalho, ao estudo, aos bens econômicos e aos valores de salários que os homens têm.

De acordo com a pesquisa "Juventudes e Sexualidade no Brasil", publicada pela UNESCO em 2004, identificou-se que 39,6\% dos meninos não gostariam de ter um colega de classe homossexual. Isso nos mostra que está mais do que na hora de falar do assunto nas salas de aula e para se evitar o constrangimento, assédio ou bullying por parte dos alunos, a família e a escola podem e devem discutir com os estudantes sobre a necessidade e a obrigação de respeitar as diferenças e de refletir sobre como quem não tem o "comportamento padrão" imposto pela sociedade sofre muito. Falar dos diferentes tipos de orientação sexual, que é a atração afetiva pelo mesmo sexo ou identificação física e psicológica com o sexo oposto, no ambiente escolar faz parte disso. De acordo com o estudo "Diversidade Sexual e Homofobia no Brasil", da Fundação Perseu Abramo, o ambiente escolar é o melhor lugar para por fim à homofobia, pois os resultados da pesquisa mostram que, enquanto metade dos brasileiros que nunca frequentou a escola assume comportamentos homofóbicos, apenas um em cada dez brasileiros que cursaram o ensino superior apresenta o mesmo comportamento.

\section{Considerações Finais}

A escola é constituída e edificada por toda a sua comunidade, assim como o gestor, a equipe diretiva, os funcionários, pais, alunos e professores têm seus papéis na organização e sucesso em todas as atividades no âmbito escolar. Sendo necessário que toda comunidade esteja envolvida na implementação e construção do conhecimento e desenvolvimento dos alunos.

O professor deve atuar de forma imparcial, mas sempre ressaltando e fazendo prevalecer o respeito com as percepções dos alunos e suas individualidades, os instigando e auxiliando na desconstrução de preconceitos e ideias prontas e pré-concebidas. O aluno deve ser estimulado a pensar, refletir e perceber tudo que o rodeia, os costumes, o racismo, a homofobia, as desigualdades, as diferentes percepções que existem em sociedade e principalmente a respeitar e compreender que todos temos nossas individualidades e que temos os mesmos direitos. 
A abordagem do assunto nas escolas pode até deixar alguns pais receosos, mas é necessário entender que é importante que o respeito às diferenças esteja presente no currículo, considerando sempre os direitos e deveres dos cidadãos e do respeito e à diversidade humana. Informar é o primeiro passo para a quebra do preconceito. Deve-se priorizar em sala de aula a inclusão e fazer com que todos os alunos sejam de forma igualitária, independente de qual gênero este se identifique.

Assim, concluo que a discussão aberta sobre as questões de gênero é de fundamental importância na construção do ser social que é o aluno, pois a sua formação e seu modo de agir afetam diretamente todo o meio em que ele está inserido. Deve-se valorizar o caráter, os sentimentos e as ações das pessoas, sem forçá-las a se encaixar em padrões ou discriminá-las por suas opções e sexualidade. Desse modo, se construirá uma sociedade mais maleável, menos discriminatória e violenta, na qual as pessoas tenham a liberdade e o respeito para se descobrirem e se construírem de acordo com as suas vontades e crenças.

\section{Referências}

AUAD, Daniela. Educar meninas e meninos: relações de gênero na escola. São Paulo: Contexto, 2006. 96 p.

BEAUVOIR, Simone de. $O$ segundo sexo. Disponível em <https://ensaiosdegenero.wordpress.com/tag/simone-de-beauvoir/page/2/> Acesso em: 15 out 2016.

DIZEM ESPECIALISTAS, Discussão de gênero nas escolas ajuda a combater violência. Disponível em <http://www2.camara.leg.br/camaranoticias/noticias/EDUCACAO-ECULTURA/499647-DISCUSSAO-DE-GENERO-NAS-ESCOLAS-AJUDA-ACOMBATER-VIOLENCIA,-DIZEM-ESPECIALISTAS.html> Acesso em 11 de Nov 2016.

GENEROS, A igualdade de. Disponível em <https://www.projetoredacao.com.br/temas-deredacao/o-que-e-uma-familia/a-igualdade-de-generos/469> Acesso em: 12 de Nov 2016.

SEXUALIDADE, Porque a educação deve discutir gênero e. Disponível em $<$ http://portal.aprendiz.uol.com.br/2015/06/25/por-que-a-educacao-deve-discutir-genero-esexualidade-listamos-7-razoes/> Acesso em: 16 out 2016.

SEXUALIDADE, relações de gênero. Disponível em <http://monografias.brasilescola.uol.com.br/pedagogia/relacoes-genero-sexualidade.htm> Acesso em: 11 de Nov 2016 